\title{
Infectious Spondylodiscitis by Uncommon Pathogens: A Pitfall of Empirical Antibiotics
}

\author{
Seung Han Yu, Dong Hwan Kim, Hwan Soo Kim, Kyoung Hyup Nam, \\ Byung Kwan Choi, In Ho Han \\ Department of Neurosurgery and Medical Research Institute, Pusan National University Hospital, \\ Pusan National University College of Medicine, Busan, Korea
}

\begin{abstract}
Objective: The goal of this study is to evaluate the prevalence of spondylodiscitis (SD) caused by uncommon pathogens and review the efficacy of the treatment strategy including the coverage by usual empirical broad-spectrum antibiotic therapy.

Methods: Ninety-nine consecutive patients diagnosed and treated for infectious SD between January 2007 to May 2015 were reviewed retrospectively. The prevalence of uncommon SD, predisposing factors, antibiotics sensitivity, and clinical outcome were analyzed in comparison with that of common SD.

Results: Among 99 patients, 68 patients were culture positive. Out of 68 patients with positive culture results, 54 of them (79.4\%) were common pathogen and $14(20.6 \%)$ were uncommon pathogen. Postoperative SDs were significantly prevalent in uncommon SD (42.9\%) than common SD (27.8\%). Recurrence rate was higher in uncommon pathogen SD (14.3\%) than common SD group $(2.3 \%)$, and it showed statistically significant difference $(p=0.025)$. Empirical antibiotics of vancomycin and 3rd or 4th generation cephalosporin covered $100 \%$ of nontuberculous common SD and $14.3 \%$ of uncommon SD.

Conclusion: In our study, the prevalence of uncommon SD was relatively high uncommon (20.5\% of culture positive SD and $14.1 \%$ of total cases) and the coverage rate of empirical antibiotics for them were only $14.3 \%$. In particular, the possibility of SD with fun gal, polymicrobial, or multiple drug resistant organism should be considered in SD unresponsive to broad spectrum antibiotics therapy.
\end{abstract}

Key Words: Spondylodiscitis · Pathogens · Antibiotics

\section{INTRODUCTION}

Infectious spondylodiscitis (SD) is an infection of intervertebral discs and adjacent vertebral bodies ${ }^{7,10)}$. Various organisms including bacteria, tuberculosis, fungi, and parasites can cause $\mathrm{SD}^{7}$. In the past, tuberculosis infection was the major cause of spinal infections ${ }^{5,7,10,15)}$. However, nowadays, the majority of spinal infections are bacterial monomicrobial ${ }^{5,7,9,15)}$. Staphylococcus aureus, Escherichia coli, Proteus, Klebsiella, Pseudomonas aeruginosa, Coagulase negative Staphylococcus, streptococci, enterococci, and Mycobacterium tuberculosis were discussed as common pathogens in majority of literatures $3,5,6,9,11,13-15,18,20)$. Empirical antibiotics have been used to focus on these common pathogens. Unfortunately, uncommon

\footnotetext{
- Received: March 21, 2016 • Revised: July 27, 2016

- Accepted: July 29, 2016

Corresponding Author: In Ho Han

Department of Neurosurgery, Pusan National University Hospital,

Pusan National University College of Medicine, 179 Gudeok-ro, Seo-gu, Busan 49241, Korea

Tel: +82-51-240-7257, Fax: +82-51-244-0282

E-mail: farlateral@hanmail.net

$\circledast$ This is an open access article distributed under the terms of the Creative Commons Attribution Non-Commercial License (http://creativecommons.org/licenses/by-nc/4.0/) which permits unrestricted non-commercial use, distribution, and reproduction in any medium, provided the original work is properly cited.
}

pathogens could be unresponsive to these empirical antibiotics resulting in treatment failure.

There are case reports on spinal infections cause by individual uncommon pathogens, but large studies encompass uncommon pathogens are rare. The goal of this study is to evaluate the prevalence of SD by uncommon pathogens and the efficacy of treatment strategy including empirical broad-spectrum antibiotics therapy in comparison with common SD.

\section{MATERIALS AND METHODS}

Ninety-nine consecutive patients treated for infectious SD in a single tertiary hospital from January 2007 to May 2015 were reviewed retrospectively. The diagnosis of infectious spondylitis was based on presentation of clinical symptoms, laboratory abnormalities (white blood cell counts, C-reactive protein, erythrocyte sedimentation rate), radiographic abnormalities, microbiological results and pathologic findings.

S. aureus, E. coli, Proteus, Klebsiella, P. aeruginosa, Coagulase negative Staphylococcus, streptococci, enterococci, and M. tuberculosis were discussed as common pathogens in majority of literatures $3,5,6,9,11,13-15,18,20)$. We defined uncommon pathogens as every pathogen except the common pathogens mentioned above, that includes rare bacterial, fungal, and parasitic organisms. 
Patient demographics, predisposing factors such as systemic illness and previous history of spinal procedure or surgery, etiological organisms and its sensitivity to empirical antibiotics, and clinical outcome including mortality, hospitalization day, cure rate, recurrence, and need for reconstructive surgery were analyzed to compare uncommon SD group with common SD group. Statistical analyses were performed using IBM SPSS Statistics ver. 22.0 (IBM Co., Armonk, NY, USA). The p-values were generated using Mann-Whitney test and p-values less than 0.05 were considered significant.

Each patient was treated with various antibiotics, but we assumed that they were treated with vancomycin and 3rd or 4th generation cephalosporin for the empirical antibiotics before identification of organism, which are one of the most broad spectrum antibiotics, in the analysis of the empirical antibiotics treatment efficacy. Patients with tuberculosis spondylitis (with either microbiological or radiological confirmation) were excluded from antibiotics efficacy analysis, because they tend to have unique clinical, radiological features to differentiate them from pyogenic infections, relatively sensitive diagnostic tools including acid fast stains and reverse transcription-polymerase chain reaction, and require entirely different medications ${ }^{7,9,15,17,20)}$. Patients were treated for various periods of time, however, clinical improvements, normalization of inflammatory marker, improvement on imaging follow-up were required for cessation of treatment.

\section{RESULTS}

\section{Patient Demographics and Risk Factors}

Of 99 patients who fulfilled inclusion criteria, 55 (55.6\%) were male and $44(44.4 \%)$ were female with a mean age of
60.8 years. There were 68 cases with positive culture results, 54 of them (79.4\%) were common pathogen and $14(20.6 \%)$ were uncommon pathogen. Thirty $(55.6 \%)$ were male and the mean age was 61.3 years in the common pathogen group. Ten (71.4\%) were male and the mean age was 60.1 years in the uncommon pathogen group.

Systemic illness including diabetes, hepatic failure, Cushing syndrome, renal failure, heart failure in common pathogen group, and uncommon pathogen group were noted in 15 (55.6 $\%)$ and 5 cases (33.3\%), respectively. There was no statistically significant difference $(\mathrm{p}=0.559)$. Twenty-seven $(50 \%)$ of common pathogen group and $7(50 \%)$ of uncommon pathogen group had history of previous spinal invasive procedures adjacent to the lesion such as acupuncture, epidural blocks, spinal anesthesia, skin grafts, catheter insertions. History of previous spinal surgery was much higher in uncommon SD group (42.9 $\%)$ than in common SD group (27.8\%), and it was statistically significant $(\mathrm{p}=0.009)$ (Table 1$)$.

\section{Etiologic Organism}

Among 99 patients, 64 had open and 35 had percutaneous (fluoroscopic or ultrasound guided) biopsies. The causative organism was confirmed by in 68 cases $(68.6 \%)$. Culture positive rates for open and percutaneous procedures were 78.1\% (50 of 64 ) and $51.4 \%$ (18 of 35$)$, respectively.

There were 14 cases (20.5\% of culture positive SD and 14.1\% of total cases) of SD caused by uncommon pathogens. Microorganisms were: Abiotrophia defectica, Acinectobacter baumanni, Bacteroides fragilis, Haemophilus parainfluenza with Corynebacterium afermentans, Porphyromonas gingivalis, Serratia marcescens, 3 cases of Candida with coinfected bacterial infection, 2 Candida species, 3 Aspergillus infections (Table 2).

Table 1. Comparison of demographics, predisposing factors, and clinical outcome in patients with common SD and uncommon SD

\begin{tabular}{lccc}
\hline \hline Variable & Common & Uncommon & p-value \\
\hline No. of the patients & 54 & 14 \\
Mean age (yr) & 60.3 & 60.1 \\
Male sex & $30(55.6)$ & $10(71.4)$ \\
Systemic illness & $15(27.8)$ & $5(33.3)$ & $7(50)$ \\
Previous spinal procedure & $27(50)$ & $6(42.9)$ & 0.559 \\
Previous spinal surgery & $15(27.8)$ & $1(7)$ & 0.060 \\
Mortality & $2(2.3)$ & 68.4 & 0.009 \\
Mean hospitalization day & 107 & $13(92.9)$ & 0.072 \\
Cure & $52(92.6)$ & $2 / 14(14.3)$ & 0.324 \\
Sensitivity to empirical antibiotics & $35 / 35(100)$ & $2(14.3)$ & 0.699 \\
Recurrence & $2(2.3)$ & $2(14.3)$ & 0.000 \\
Need for reconstruction & $9(35.2)$ & & 0.134 \\
\hline
\end{tabular}

Values are presented as number (\%) unless otherwise indicated. SD, spondylodiscitis.

"Tuberculous SD were excluded. 
Of 54 cases with common SD (79.4\% of culture positive SD and $54.5 \%$ of total cases), 33 were bacterial monomicrobial, 2 were bacterial polymicrobial, 19 were tuberculous.

\section{Treatment and Outcome}

The cure rate of common and uncommon SD group was 96.3 $\%$ and $92.9 \%$, respectively. Two patients in common SD group died of aggravated pneumonia and hepatic failure, and one pa- tient in uncommon SD group died of sepsis. The mean duration of hospitalization was 107 days and 68.4 days for common and uncommon pathogen group. Statistical analysis showed no significant difference in mortality, cure rate and duration of hospitalization between the 2 groups $(\mathrm{p}>0.05)$ (Table 1$)$.

Only 2 cases (14.3\%) in uncommon SD group were covered by empirical antibiotics whereas every 35 cases (100\%) of nontuberculous cases of common SD group were covered by vancomycin and 3rd or 4th generation cephalosporin (Tables 1, 2).
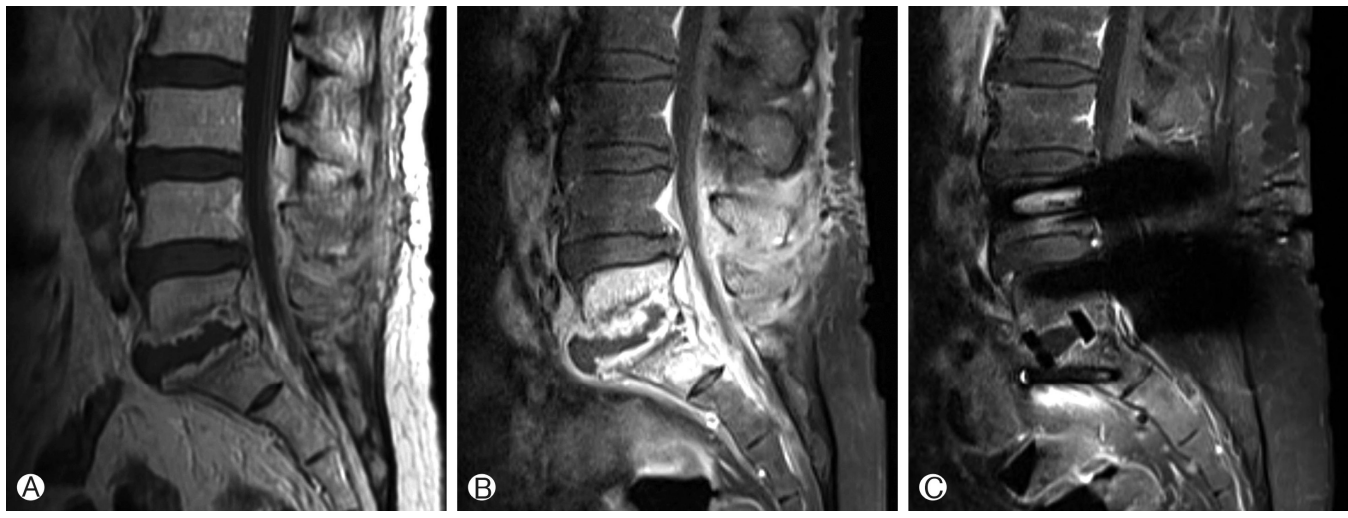

Fig. 1. (A) Enhanced T1 magnetic resonance image of lumbar spine at the time of diagnosis. (B) After 3 weeks treatment of empirical ceftriaxone and ciprofloxacin without biopsy, follow-up image showed aggravation of spondylitis. (C) Eighteen-month follow-up image after administration of fluconazole for Aspergillus fumigatus. Reconstructive fusion operation was performed and total control of infection was achieved.

Table 2. Summary of patients with uncommon pathogen

\begin{tabular}{|c|c|c|c|c|c|c|c|}
\hline $\begin{array}{l}\text { Case } \\
\text { No. }\end{array}$ & $\begin{array}{l}\text { Sex/ } \\
\text { age }\end{array}$ & Etiological organism & Initial treatment & $\begin{array}{c}\text { Treatment after } \\
\text { culture }\end{array}$ & Systemic illness & $\mathrm{HD}$ & Outcome \\
\hline 1 & $\mathrm{~F} / 43$ & Abiotrophia defectica & VAN & VAN & - & 51 & Cured \\
\hline 2 & $\mathrm{M} / 70$ & Acinectobacter baumanni & Meropenem & Levofloxacin & - & 73 & Cured \\
\hline 3 & $\mathrm{M} / 70$ & Aspergillus spp & VAN & Amp B & - & 88 & Cured \\
\hline 4 & $\mathrm{M} / 59$ & Aspergillus spp & Ampicillin/sulbactam & VOR & Pulmonary aspergillosis & 91 & Recurred \\
\hline 5 & $\mathrm{~F} / 59$ & Aspergillus fumigatus & $\mathrm{CFT}+\mathrm{CPR}$ & VOR & - & 61 & Cured \\
\hline 6 & $\mathrm{~F} / 39$ & Bacteroides fragilis & $\begin{array}{l}\text { Ceftazidime }+ \\
\text { netilmicin }\end{array}$ & MTZ & - & 36 & Cured \\
\hline 7 & $\mathrm{M} / 55$ & Candida albicans & Teicoplanin & FCZ & Neutropenia & 36 & Cured \\
\hline 8 & $\mathrm{M} / 67$ & Candida glabrata & $\mathrm{VAN}+\mathrm{CPR}$ & AMP & Diabetes & 75 & Recurred \\
\hline 9 & $\mathrm{M} / 81$ & $\begin{array}{l}\text { Staphylococcus epidermidis + } \\
\text { Staphylococcus capitis + Candida spp }\end{array}$ & $\mathrm{VAN}+\mathrm{RFP}+\mathrm{MTZ}$ & VAN + FCZ & Skin fungal infection & 85 & Cured \\
\hline 10 & $\mathrm{M} / 74$ & Enterococcus faecalis + Candida albicans & $\mathrm{CFT}+\mathrm{CPR}$ & $\begin{array}{l}\mathrm{VAN}+\mathrm{FCZ}+ \\
\text { ceftaxidime }\end{array}$ & - & 168 & Cured \\
\hline 11 & $\mathrm{M} / 74$ & Enterococcus faecium + Candida albicans & $\mathrm{VAN}+\mathrm{CFT}$ & $\begin{array}{l}\mathrm{VAN}+\mathrm{CFT}+ \\
\mathrm{FCZ}\end{array}$ & Renal cell carcinoma & 20 & $\begin{array}{c}\text { Died of } \\
\text { sepsis }\end{array}$ \\
\hline 12 & $\mathrm{M} / 61$ & $\begin{array}{l}\text { Haemophilus parainfluenzae }+ \\
\text { Corynebacterium afermentans }\end{array}$ & VAN + cefepime & $\mathrm{VAN}+\mathrm{CFT}$ & - & 89 & Cured \\
\hline 13 & $\mathrm{M} / 51$ & Porphyromonas gingivalis & $\mathrm{VAN}+\mathrm{CFT}+\mathrm{MTZ}$ & $\mathrm{CFT}+\mathrm{MTZ}$ & - & 35 & Cured \\
\hline 14 & $\mathrm{M} / 47$ & Serratia marcescens & VAN + CFT & Meropenem & - & - & Cured \\
\hline
\end{tabular}

HD, hospitalization day; AMP, amphotericin B; CFT, ceftriaxone; CPR, ciprofloxacin; FCZ, fluconazole; RFP, rifampicin; MTZ, metronidazole; VAN, vancomycin; VOR, voriconazole. 
Patients with negative culture results were treated with broad spectrum antibiotics except for 2 patients who showed typical magnetic resonance finding of tuberculosis spondylitis and treated with antituberculosis medication. All of 31 patients with negative microbiological results showed clinical improvement with the use of antibiotics.

Recurrence rate was higher in uncommon pathogen SD (14.3 \%) than common SD group (2.3\%), and it showed statistically significant difference $(p=0.025)$. Reconstructive fusion operations were performed because of progressive deformity or intractable pain despite treatment for 19 (35.2\%) in common SD group and $2(14.3 \%)$ in uncommon SD group (Table 1).

\section{Case Rresentation}

A 59-year-old female (case number 5) with a history of discectomy 2 months before the symptom onset was transferred from local clinic with high fever and severe back pain. She was diagnosed with SD (Fig. 1A) and treated with empirical antibiotics treatment of ceftriaxone and ciprofloxacin for 3 weeks in local clinic without biopsy. Follow-up image shows aggrava- tion of the disease (Fig. 1B). Open biopsy was performed and Aspergillus fumigatus was identified. Intravenous voriconazole for 2 weeks and oral voriconazole for 9 months was administered. Reconstructive fusion operation was performed later. Eighteen-month follow-up image shows total control of the SD (Fig. 1C).

\section{DISCUSSION}

Infectious spondylitis is not a common disease, consisting $2 \%-7 \%$ of cases of osteomyelitis ${ }^{2,3,5,7}$. However, several studies have reported increased incidence possibly due to increasing average age, immunodeficiency, diabetes, drug abuse, various invasive procedure, spinal surgeries, and better diagnostic tools ${ }^{2,3,5,7,10,12)}$.

Tuberculous SD was believed to be the leading cause of spinal infection in developing countries including Korea ${ }^{5,7,15}$. In our study, $M$ tuberculosis was the single most common causative organism (27.9\%). Then again, bacterial pyogenic infection all together (60.3\%) showed almost 2 folds higher incidence and uncommon SD (20.6\%) had at least a half incidence. With the greater use of immunosuppressants, prolonged use of broad-spectrum antibiotics, indwelling catheters, and the higher prevalence of chronic debilitating diseases, the epidemiology and etiology appear to be changing ${ }^{8,919)}$. It is also important that these once-rare pathogens can be resistant to antibiotics that are currently used ${ }^{1,8)}$.

Many reports and guidelines strongly recommend identification of the pathogen before the start of antibiotics treatment, except when the patient is in a septic condition ${ }^{1,47,19)}$. Various procedures from simple blood culture, percutaneous biopsy, and excisional biopsy to even reconstructive instrumentation can be performed. However, in our study, only 54.9\% of the patients who were transferred from other hospitals were treated with various IV antibiotics without an attempt to acquire microbiological identification of the causative organism. This seems inappropriate since a considerably high portion of $\mathrm{SD}$ is resistant to even the most broad-spectrum antibiotics we use. In addition, such treatment can decrease the sensitivity of culture ${ }^{1,9)}$.

In our study, uncommon SD was not-so-uncommon (20.5\% of culture positive SD and $14.1 \%$ of total cases) within modern population, and only $14.3 \%$ of them were proved to be sensitive to vancomycin and 3rd or 4th generation cephalosporin. In addition, the ratio of presence of previous spinal surgery in uncommon SD is significantly higher than that of common SD $(p=0.009)$, which is contrary to popular belief that etiology of postoperative infections is most likely one of skin microbiota. Positive ratio of recurrence was the only parameter with statistically significant difference between two groups in clinical outcome. Two cases (case numbers 4 and 8 ) recurred after cessation of parenteral antibiotics were both fungal infection (Aspergillus and Candida), which require much longer periods of treatment and recur more often. Sufficient duration of treatment and careful observation in follow-up periods are required for uncommon SD.

Physicians should always consider uncommon pathogens with multiple drug resistance, fungal organisms, and polymicrobial infections especially when treating patients with known risk factors or experiencing treatment failure or recurrence ${ }^{1,6,16,19)}$. In addition, the importance of identification of the pathogen before the start of antibiotics treatment must be emphasized.

\section{CONCLUSION}

In our study, the prevalence of uncommon SD was relatively high uncommon (20.5\% of culture positive SD and $14.1 \%$ of total cases) and the coverage rate of empirical antibiotics for them were only $14.3 \%$. In particular, the possibility of uncommon pathogen with fungal, polymicrobial, or multiple drug resistant organism should be considered in especially when treating patients with known risk factors or experiencing treatment failure or recurrence.

\section{CONFLICT OF INTEREST}

No potential conflict of interest relevant to this article was reported.

\section{ACKNOWLEDGMENTS}

This study was supported by clinical research grant (2016), Pusan National University Hospital.

\section{REFERENCES}

1. Berbari EF, Kanj SS, Kowalski TJ, Darouiche RO, Widmer AF, 
Schmitt SK, et al: 2015 Infectious Diseases Society of America (IDSA) Clinical Practice Guidelines for the diagnosis and treatment of native vertebral osteomyelitis in adults. Clin Infect Dis 61:e26-46, 2015

2. Bettini N, Girardo M, Dema E, Cervellati S: Evaluation of conservative treatment of non specific spondylodiscitis. Eur Spine J 18 Suppl 1:143-150, 2009

3. Butler JS, Shelly MJ, Timlin M, Powderly WG, O'Byrne JM: Nontuberculous pyogenic spinal infection in adults: a 12-year experience from a tertiary referral center. Spine (Phila Pa 1976) 31:2695-2700, 2006

4. Chahoud J, Kanafani Z, Kanj SS: Surgical site infections following spine surgery: eliminating the controversies in the diagnosis. Front Med (Lausanne) 1:7, 2014

5. Cheung WY, Luk KD: Pyogenic spondylitis. Int Orthop 36:397404, 2012

6. Cottle L, Riordan T: Infectious spondylodiscitis. J Infect 56: 401-412, 2008

7. Duarte RM, Vaccaro AR: Spinal infection: state of the art and management algorithm. Eur Spine J 22:2787-2799, 2013

8. Garbino J, Schnyder I, Lew D, Bouchuiguir-Wafa K, Rohner P: An unusual cause of vertebral osteomyelitis: Candida species. Scand J Infect Dis 35:288-291, 2003

9. Gouliouris T, Aliyu SH, Brown NM: Spondylodiscitis: update on diagnosis and management. J Antimicrob Chemother 65 Suppl 3:iii11-24, 2010

10. Guerado E, Cervan AM: Surgical treatment of spondylodiscitis. An update. Int Orthop 36:413-420, 2012
11. Hegde V, Meredith DS, Kepler CK, Huang RC: Management of postoperative spinal infections. World J Orthop 3:182-189, 2012

12. Heo W, Kang DH, Park KB, Hwang SH, Park IS, Han JW: Is titanium mesh cage safe in surgical management of pyogenic spondylitis? J Korean Neurosurg Soc 50:357-362, 2011

13. Kim DH, Kim HS, Nam KH, Choi BK, Han IH: Adverse drug reactions of long-term intravenous antibiotics in patients with pyogenic spondylitis. Korean J Spine 11:113-116, 2014

14. Kim SS, Kang DH, Yoon JW, Park H, Lee CH, Hwang SH: Surgical treatment of pyogenic spondylitis with the use of freezedried structural allograft. Korean J Spine 11:136-144, 2014

15. Lee KY: Comparison of pyogenic spondylitis and tuberculous spondylitis. Asian Spine J 8:216-223, 2014

16. Lee SW, Lee SH, Chung HW, Kim MJ, Seo MJ, Shin MJ: Candida spondylitis: comparison of MRI findings with bacterial and tuberculous causes. AJR Am J Roentgenol 201:872-877, 2013

17. Moon MS: Tuberculosis of spine: current views in diagnosis and management. Asian Spine J 8:97-111, 2014

18. Sapico FL, Montgomerie JZ: Vertebral osteomyelitis. Infect Dis Clin North Am 4:539-550, 1990

19. Skaf GS, Domloj NT, Fehlings MG, Bouclaous CH, Sabbagh AS, Kanafani ZA, et al: Pyogenic spondylodiscitis: an overview. J Infect Public Health 3:5-16, 2010

20. Yoon YK, Jo YM, Kwon HH, Yoon HJ, Lee EJ, Park SY, et al: Differential diagnosis between tuberculous spondylodiscitis and pyogenic spontaneous spondylodiscitis: a multicenter descrip tive and comparative study. Spine J 15:1764-1771, 2015 